\title{
Optimal Monetary Policy, Exchange Rate Misalignments and Incomplete Financial Markets*
}

\author{
Ozge Senay ${ }^{\dagger}$ and Alan Sutherland ${ }^{\ddagger}$
}

November 2018

\begin{abstract}
Recent literature shows that, when international financial trade is restricted to autarky or a single bond, there are internal and external welfare trade-offs that imply optimal monetary policy, in principle, deviates from inflation targeting in order to offset real exchange rate misalignments. This paper develops a more realistic model of incomplete markets, where there is international trade in multiple assets. The analysis shows that the presence of multiple assets creates a potentially powerful interaction between monetary policy and household portfolio allocation. This interaction is, by definition, not present when there is financial autarky or a single tradeable bond and this paper shows that the interaction with portfolio allocation can imply that optimal monetary policy generates a quantitatively much more significant stabilisation of the real exchange rate gap than implied by simpler models of financial market incompleteness.

Keywords: Optimal monetary policy, Financial market structure, Country Portfolios

JEL: E52, E58, F41
\end{abstract}

${ }^{*}$ We are grateful to Giancarlo Corsetti, Charles Engel, Oliver de Groot, Kemal Ozhan and two anonymous referees for many helpful comments on an earlier draft of this paper. This research is supported by ESRC Award Number ES/I024174/1.

$\dagger$ University of St Andrews. Address: School of Economics and Finance, University of St Andrews, St Andrews, KY16 9AL, UK. E-mail: os12@st-and.ac.uk Tel: +44 1334462422.

${ }^{\ddagger}$ CEPR and University of St Andrews. Address: School of Economics and Finance, University of St Andrews, St Andrews, KY16 9AL, UK. E-mail: ajs10@st-and.ac.uk Tel: +44 1334462446. 


\section{Introduction}

To what extent should the design of monetary policy rules explicitly account for open economy factors such as current account imbalances or exchange rate misalignments? Recent literature has emphasised the key role of imperfections in international financial markets in creating a trade-off between internal and external objectives of monetary policy. The aim of this paper is to extend the analyse of this question to a model with international trade in multiple assets but where there are insufficient assets to hedge against all sources of shocks simultaneously. We show that monetary policy can have a significant effect on welfare via its impact on portfolio allocation. This provides a strong incentive to direct monetary policy away from internal objectives (i.e. inflation stabilisation) and towards an external objective (i.e. stabilisation of the real exchange rate around its first-best level).

This paper is a contribution to a long-running literature on optimal monetary policy in open economies. The early literature emphasised that open economy factors need have no explicit role in the design of optimal cooperative monetary policy rules. For instance, Benigno and Benigno (2003) showed that optimal cooperative monetary policy should focus on targeting the rate of inflation of producer prices. ${ }^{1}$ These authors demonstrate that a policy of inflation targeting is sufficient to close all internal and external welfare gaps. There is therefore no trade-off between internal and external policy objectives. ${ }^{2}$ This early open economy literature, however, focused on models where international financial markets are complete. Households can therefore fully hedge against country specific income shocks. More recent literature has begun to analyse monetary policy in open economy models where financial markets are incomplete. For instance, Corsetti et al $(2010,2018)$ analyse cooperative monetary policy in a context where international financial trade is absent or is restricted to a single non-contingent bond. They show that, in contrast to the previous literature, when international financial markets are incomplete there are significant internal and external trade-offs that prevent optimal cooperative

\footnotetext{
${ }^{1}$ In this paper we focus on optimal cooperative policy, i.e. a world where policy is set at a world level in order to maximise world welfare. In some special cases, see for instance Clarida et al (2002) and Gali and Monacelli (2005), optimal cooperative policy is identical to non-cooperative policy, but this is not true in general.

${ }^{2}$ This early literature is in effect a direct extension to an open economy setting of the basic closed economy results of Woodford (2003) and Benigno and Woodford (2005). The only difference between the closed and open economy results is in the choice of price index for the inflation target - consumer prices for a closed economy and producer prices for an open economy.
} 
policy from simultaneously closing all welfare relevant gaps. ${ }^{3}$

The basic intuition for the Corsetti et al (2010, 2018) results is simple to explain. A policy of producer price inflation targeting reproduces the flexible price outcome and therefore eliminates the welfare costs associated with staggered price setting. But the flexible price equilibrium is not fully optimal because international financial markets are imperfect and thus cross-country income risks are not optimally shared. A corollary of this is that the real exchange rate and trade balance will deviate from their first best outcomes. Corsetti et al $(2010,2018)$ show that optimal cooperative policy deviates from inflation targeting and takes account of external welfare gaps and acts to offset "exchange rate misalignments."

The results in Corsetti et al $(2010,2018)$ clearly point to a potentially important deviation from the standard policy prescription of inflation targeting. There is however a significant limitation to Corsetti et al's work. In Corsetti et al (2010) the analysis of imperfect international financial markets is restricted to a model with financial autarky, while in Corsetti et al (2018) the analysis of imperfect financial markets is represented by a single-bond economy. These structures provide important insights into the implications of imperfect financial trade but they are obviously not a good representation of modern international financial markets.

The main objective of the current paper is to analyse optimal monetary policy in more general models of imperfect international financial trade than those considered in Corsetti et al (2010, 2018). Our analysis begins with a simple model which adds one extra asset compared to Corsetti et al (2010, 2018), so there is trade in two nominal bonds. Despite the additional asset our model continues to be one where financial markets are incomplete (because there are not sufficient assets to hedge against all shocks). We show that this small change in financial market structure has an important qualitative and a potentially large quantitative effect on optimal cooperative policy compared to Corsetti et al (2010, 2018). Corsetti et al's (2010, 2018) analysis shows that optimal cooperative policy deviates from inflation targeting most significantly for small values of the international trade elasticity and when prices are set in the currency of the consumer (local currency pricing, LCP). At higher values of the trade elasticity the deviations

\footnotetext{
${ }^{3}$ Corsetti et al $(2010,2018)$ focus on optimal monetary policy in a symmetric two-country world. Benigno (2009) analyses an asymmetric world with incomplete financial markets and shows how optimal monetary policy differs between net-debtor and net-creditor countries. De Paoli (2010) analyses monetary policy for a small open economy and shows how optimal policy depends on the degree of financial integration.
} 
from inflation targeting are quantitatively small. In contrast, our results show that, with international trade in two bonds, there are quantitatively large deviations from inflation targeting for a wide range of values of the trade elasticity. These large deviations arise in terms of welfare, the optimal policy rule and variances of critical variables. In particular, we show that optimal cooperative policy implies a significant stabilisation of the real exchange rate gap relative to inflation targeting

We are further able to show that the critical difference between the single-bond case and the two-bond case arises specifically because, in the two-bond case, monetary policy is able to change portfolio returns and the composition of the equilibrium portfolio. In effect monetary policy achieves a significant amount of leverage on risk sharing through its influence on portfolio returns and portfolio allocation. This is a mechanism which does not exist in the single-bond case.

Having demonstrated the basic result in a simple model with a limited range of stochastic shocks, two nominal bonds and a very simple policy rule, we extend the analysis in a number of directions. We add further sources of shocks, we allow for trade in equities as well as nominal bonds and we consider a more general version of the policy rule. We also consider local currency pricing. We show that our basic result carries over to these more general cases.

Because our model allows for international trade in multiple assets it is obviously necessary to compute equilibrium gross portfolios. As just explained, a crucial mechanism at work in our model is that the size and composition of these portfolios depends on the properties of the monetary rule. There is therefore an interaction between policy choice and portfolio choice. Equilibrium portfolios are computed using techniques developed in recent literature (see Devereux and Sutherland (2010a, 2011a) and Tille and van Wincoop (2010)). The combining of these techniques with the analysis of optimal policy is an important innovation of this paper. ${ }^{4}$

The paper proceeds as follows. The model is presented in Section 2. Our definition of welfare and the characterisation of monetary policy is described in Section 3 and our methodology for deriving optimal policy rules in the presence of endogenous portfolio choice is described in Section 4. The main results of the paper are presented in Section 5 and the results from an extended version of the model are described in Section 6 . Section

\footnotetext{
${ }^{4}$ Devereux and Sutherland (2008) consider a simple case where optimal monetary policy can be analysed alongside endogenous portfolio choice. They show that, in a special restricted case, strict inflation targeting reproduces the full risk sharing outcome, so there is no trade-off between internal and external policy objectives in that very restricted case.
} 
7 concludes the paper.

\section{The Model}

Our main analysis is based on a model of two countries with two main sources of shocks. In later sections we consider an extended version of the model with a number of other sources of shocks. The model shares many of the same basic features of the closed economy models developed by Christiano et al (2005) and Smets and Wouters (2003). It is based on the open economy model developed in Devereux et al (2014).

Households consume a basket of home and foreign produced final goods. Final goods are produced by monopolistically competitive firms which use intermediate goods as their only input. Final goods prices are subject to Calvo-style contracts. Intermediate goods are produced by perfectly competitive firms using labour and real capital as inputs. Intermediate goods prices are perfectly flexible. The capital stock is fixed. Households supply homogeneous labour to perfectly competitive firms producing intermediate goods.

In the benchmark version of the model we allow for shocks to home and foreign TFP and home and foreign household preferences and there is international trade in nominal bonds denominated in the currency of each country. Given the range of shocks, trade in two bonds is be sufficient to provide full risk sharing. This is therefore a model of incomplete financial markets. This is a key feature of the model.

The following sections describe the home country in detail. The foreign country is identical. An asterisk indicates a foreign variable or a price in foreign currency.

\subsection{Households}

Household $z$ in the home country maximizes a utility function of the form

$$
U_{t}=E_{t} \sum_{i=0}^{\infty} \beta_{i}\left\{\Psi_{t+i} \frac{C_{t+i}^{1-\rho}(z)}{1-\rho}-\Delta \frac{H_{t+i}^{1+\phi}(z)}{1+\phi}\right\}
$$

where $\rho>0, \phi>0, \Delta>0, C(z)$ is the consumption of household $z, H(z)$ is labour supply, $\beta$ is the discount factor and $\Psi_{t}$ are stochastic shocks which affect consumption preferences. We assume $\Psi_{t}=\bar{\Psi} \exp \left(\hat{\Psi}_{t}\right)$ where $\hat{\Psi}_{t}=\eta_{\Psi} \hat{\Psi}_{t-1}+\varepsilon_{\Psi, t}, 0 \leq \eta_{\Psi}<1$ and $\varepsilon_{\Psi, t}$ is a zero-mean normally distributed i.i.d. shock with $\operatorname{Var}\left[\varepsilon_{\Psi}\right]=\sigma_{\Psi}^{2}$.

Taste shocks in the form of $\Psi_{t}$ are emphasised by Corsetti et al $(2010,2018)$ because they create a strong role for current account dynamics and thus potentially create a strong 
welfare trade-off for monetary policy when financial markets are incomplete. These taste shocks will likewise play an important role in our analysis.

The discount factor, $\beta_{i}$, is endogenous and is determined as follows

$$
\beta_{i+1}=\bar{\beta} \beta_{i}\left(\frac{C_{A, i}}{\bar{C}_{A}}\right)^{-\eta}, \beta_{0}=1
$$

where $0<\eta<\rho, 0<\bar{\beta}<1, C_{A}$ is aggregate home consumption and $\bar{C}_{A}$ is a constant. ${ }^{5}$

We define $C_{t}$ to be a consumption basket which aggregates home and foreign goods according to:

$$
C_{t}=\left[\gamma^{\frac{1}{\theta}} C_{H, t}^{\frac{\theta-1}{\theta}}+(1-\gamma)^{\frac{1}{\theta}} C_{F, t}^{\frac{\theta-1}{\theta}}\right]^{\frac{\theta}{\theta-1}}
$$

where $C_{H}$ and $C_{F}$ are baskets of individual home and foreign produced goods. The elasticity of substitution across individual goods within these baskets is $\lambda>1$. The parameter $\theta$ in (3) is the elasticity of substitution between home and foreign goods. The parameter $\gamma$ measures the importance of consumption of the home good in preferences. For $\gamma>1 / 2$, we have 'home bias' in preferences.

The price index associated with the consumption basket $C_{t}$ is

$$
P_{t}=\left[\gamma P_{H, H, t}^{1-\theta}+(1-\gamma) P_{F, H, t}^{1-\theta}\right]^{\frac{1}{1-\theta}}
$$

where $P_{H, H}$ is the price index of home goods for home consumers and $P_{F, H}$ is the price index of foreign goods for home consumers. The corresponding price indices for foreign consumers are $P_{H, F}$ and $P_{F, F}$.

The flow budget constraint of the home country household is

$$
P_{t} C_{t}+P_{t} F_{t}=w_{t} H_{t}+P_{t} \Pi_{t}+P_{t} \sum_{k=1}^{N} \alpha_{k, t-1} r_{k t}
$$

where $F_{t}$ denotes home country net external assets in terms of the home consumption basket, $w_{t}$ is the home nominal wage and $\Pi_{t}$ is profits of all home firms. The final term represents the total return on the home country portfolio where $\alpha_{k, t-1}$ represents the real external holdings of asset $k$ (defined in terms of the home consumption basket) purchased at the end of period $t-1$ and $r_{k, t}$ represents the gross real return on asset $k$. In our

\footnotetext{
${ }^{5}$ Following Schmitt-Grohe and Uribe $(2003), \beta_{i}$ is assumed to be taken as exogenous by individual decision makers. The impact of individual consumption on the discount factor is therefore not internalized. Note that this externality in principle creates a distortion in portfolio choice (in the sense that market equilibrium portfolios will differ from the welfare maximising portfolio) - but in practice this distortion is quantitively very small and has no significant implication for the analysis presented below.
} 
analysis, we initially allow for trade in $N=2$ assets; home and foreign nominal bonds. Note that $F_{t}=\sum_{k=1}^{N} \alpha_{k, t}$.

Nominal bonds are assumed to be perpetuities, so for instance, home nominal bonds represent a claim on a unit of home currency in each period into the infinite future. The real price of the home bond is denoted $Z_{B, t}$. The gross real rate of return on a home bond is thus $r_{B t+1}=\left(1 / P_{t+1}+Z_{B, t+1}\right) / Z_{B, t}$. For the foreign nominal bond, the real return on foreign bonds, in terms of home consumption, is $r_{B^{*} t+1}=\left(Q_{t+1} / Q_{t}\right)\left(1 / P_{t+1}^{*}+\right.$ $\left.Z_{B, t+1}^{*}\right) / Z_{B, t}^{*}$, where $Q_{t}=S_{t} P_{t}^{*} / P_{t}$ is the real exchange rate (where $S$ is the price of the foreign currency in terms of the home currency). ${ }^{6}$

For the purposes of comparison, we also consider a financial autarky version of the model, which implies $N=0$, and a single bond version, i.e. $N=1$, where the only internationally traded asset is a single real bond. For all financial structures we impose the assumption that the steady state net foreign asset position is zero. This outcome is implied by the assumed endogeneity of the discount factor given in (2).

\section{$2.2 \quad$ Firms}

Within each country firms are divided between final and intermediate sectors. Intermediate goods firms use labour and real capital. There is a unit mass of firms in both the final and intermediate levels.

\subsubsection{Final goods}

Each firm in the final goods sector produces a single differentiated product. Sticky prices are modelled in the form of Calvo (1983) style contracts with a probability of re-setting price given by $1-\kappa$. In the basic version of the model we assume producer currency pricing $(\mathrm{PCP})$.

If firms use the discount factor $\Omega_{t}$ to evaluate future profits, then firm $z$ chooses its prices for home and foreign buyers, $p_{H, H, t}(z)$ and $p_{H, F, t}(z)$, in home currency to maximize

$$
E_{t} \sum_{i=0}^{\infty} \Omega_{t+i} \kappa^{i}\left\{y_{H, H, t+i}(z) \frac{\left[p_{H, H, t}(z)-q_{t+i}\right]}{P_{t+i}}+y_{H, F, t+i}(z) \frac{\left[p_{H, F, t}(z)-q_{t+i}\right]}{P_{t+i}}\right\}
$$

where $y_{H, H}(z)$ is the demand for home good $z$ from home buyers and $y_{H, F}(z)$ is the

\footnotetext{
${ }^{6}$ The assumption that bonds are perpetuities has no particular significance for our results. We have experimented with a version of the model with single-period bonds and, while there are some quantitative implications, there is no systematic qualitative differences compared to the results reported below.
} 
demand for home good $z$ from foreign buyers and $q$ is the price of the intermediate good. ${ }^{7}$

\subsubsection{Intermediate goods}

The representative firm in the intermediate goods sector combines labour, $L$, and capital, $K$, to produce output $Y$ using a standard Cobb-Douglas technology, $Y_{t}=A_{t} K^{1-\mu} L_{t}^{\mu}$. We assume that the capital stock is fixed and that total factor productivity (TFP), $A_{t}$, is determined by $A_{t}=\eta_{A} A_{t-1}+\varepsilon_{A, t}$ where $\eta_{A}>0$ and $\varepsilon_{A, t}$ are zero mean normally distributed i.i.d. shocks.

The representative firm chooses $L_{t}$ to maximize the real discounted value of dividends, given by

$$
E_{t} \sum_{i=0}^{\infty} \Omega_{t+i}\left[\frac{q_{t+i}}{P_{t+i}} Y_{t+i}-\frac{w_{t+i}}{P_{t+i}} L_{t+i}\right]
$$

subject to the production function where $q$ is the price of intermediate goods. $\Omega_{t}$ is assumed to be the stochastic discount factor of shareholders of the firm. Equilibrium in the labour market implies $L_{t}=H_{t}$.

\section{Monetary Policy and Welfare}

The particular welfare measure on which we focus is the unconditional expectation of aggregate period utility. For the home economy this is defined as follows

$$
U=E\left\{\Psi \frac{C^{1-\rho}}{1-\rho}-\Delta \frac{H^{1+\phi}}{1+\phi}\right\}
$$

where time subscripts are omitted to indicate that this is a measure of unconditional expectation. Damjanovic et al (2008) argue that unconditionally expected utility provides a useful alternative to Woodford's (2003) 'timeless perspective' when analysing optimal policy problems. For the purposes of this paper, unconditional expected utility provides

\footnotetext{
${ }^{7}$ In the basic model, where international asset trade is restricted to nominal bonds, all equity is owned within each country, so the relevant discount factor for home and foreign firms is, respectively, the discount factor for home and foreign households. When there is international trade in equities the discount factor for firms will in principle be a weighted average of home and foreign household discount factors, with the weight being determined by relative portfolio holdings of equity. However, as a convenience simplification (which has trivial quantitative implications for equilibrium outcomes), even when there is international trade in equities we impose the assumption that the firm discount factor in each country corresponds to the household discount factor in each country.
} 
a simple and convenient way to compute welfare in a context where portfolio allocation is endogenous. The next section provides a more detailed discussion of the complications that arise in the simultaneous computation of welfare and equilibrium portfolios.

In common with Corsetti et al $(2010,2018)$ we focus on co-operative policy in the sense that policy rules for each country are simultaneously chosen to maximise global welfare, i.e. the sum of the home and foreign welfare measures. Note that, for simplicity, throughout the remainder of this paper we refer to 'optimal policy' or the 'optimal policy rule'. This should be understood to imply optimal cooperative policy.

We model monetary policy in the form of a 'targeting rule'. In general the optimal targeting rule is model dependent. Corsetti et al $(2010,2018)$ show that the optimal targeting rule for a model similar to ours includes measures of inflation and a number of welfare gaps. Because of the complicated interaction between policy and portfolio choice we do not derive the fully optimal policy rule for our model. Instead we use the form of the optimal rule derived by Corsetti et al (2010, 2018) as an approximation for optimal policy in our model. ${ }^{8}$

In fact, we start our analysis with the following very restricted form of targeting rule

$$
\left(\hat{P}_{Y, t}-\hat{P}_{Y, t-1}\right)+\delta_{\mathcal{D}}\left(\mathcal{D}_{t}-\mathcal{D}_{t-1}\right)=0
$$

where a hat over a variable represents its log deviation from the non-stochastic steady state and $\mathcal{D}$ is defined as

$$
\mathcal{D}=-\rho\left(\hat{C}-\hat{C}^{*}\right)+\hat{Q}-\left(\hat{\Psi}-\hat{\Psi}^{*}\right)
$$

(8) is the home-country targeting rule. There is a corresponding targeting rule for the foreign country. Given that the model is symmetric, the coefficient of the of the foreign monetary rule is assumed to be identical to the coefficient of the home rule, with appropriate changes of sign.

The targeting rule in (8) contains two terms. The first term represents producer price (PPI) inflation. The central role of inflation stabilisation in optimal policy in New

\footnotetext{
${ }^{8}$ Recently, Fanelli (2017) has developed an approximation approach which allows a combined analysis of portfolio allocation and optimal monetary policy in a simple theoretical framework which allows monetary policy to be characterised as a fully optimal targeting rule which is very similar to (8). Fanelli shows that optimal policy is a trade-off between a term which measures the output gap and price dispersion and a term which measures risk sharing. Fanelli uses this framework to investigate the impact of optimal policy on portfolio allocation and argues that there is a role for capital controls. Fanelli's analytical approach is useful for the analysis of simple models but is unlikely to be easily generalised to more complex models of the type analysed in the later sections of this paper.
} 
Keynesian models is a well-known consequence of staggered price setting. In essence, staggered price setting implies that inflation causes distortions in relative prices between goods. Inflation is thus (other things equal) welfare reducing. It is also well-known that, in the presence of PCP, the welfare-relevant measure of inflation is PPI inflation. This is captured by the first term in (8).

The second term in the targeting rule is referred to by Corsetti et al (2010, 2018) as a measure of 'demand imbalances'. It measures deviations from full risk sharing. This captures the welfare reducing effects of incomplete financial markets. To understand this term note that, if a complete set of financial instruments were available for international trade, equilibrium in financial markets would imply that the ratio of marginal utilities across countries would equal the relative price of consumption baskets, i.e.

$$
\frac{\Psi_{t}^{*} C_{t}^{*-\rho}}{\Psi_{t} C_{t}^{-\rho}}=Q_{t}
$$

or in terms of log-deviations

$$
-\left(\hat{\Psi}-\hat{\Psi}^{*}\right)-\rho\left(\hat{C}-\hat{C}^{*}\right)+\hat{Q}=0
$$

This is the well-known risk sharing condition that is standard in open-economy models with complete financial markets. It is thus clear that $\mathcal{D}$ in $(8)$ is a measure of deviations from full risk sharing. And it is clear that this term in the monetary policy rule captures the extent to which monetary policy is adjusted in order to achieve greater risk sharing.

The simple targeting rule in (8) is sufficient to capture the key trade-off in monetary policy between inflation stabilisation and deviations from risk sharing. There is just one parameter in this rule, $\delta_{\mathcal{D}}$, so the policy optimisation problem is to choose the value of $\delta_{\mathcal{D}}$ to maximise welfare (as measured by $(7)$ ).

Before proceeding to a discussion of the solution and optimisation procedure, it is worth noting that the characterisation of policy as a targeting rule is (as argued by Woodford (2003)) a convenient way to capture the welfare trade-offs faced by policy makers without the need explicitly to model policy in terms of the optimal setting of a policy instrument (such as the nominal interest rate). In cases where a instrument rule is of interest it is, in principle, easy to derive such a rule once the optimal targeting rule has derived. But note that it is often the case (as is true in the present model) that the optimal targeting rule involves 'gap variables' - i.e. the difference between the actual and the firstbest level of a variable. This raises a practical problem for translating the targeting rule into an implementable rule for monetary policy since the optimal instrument rule would 
then require full knowledge by the policymaker of the exogenous shocks that affect the first-best level of variables. In the case of the model described above this would imply that TFP and taste shocks are directly observable by policymakers. We acknowledge that this is a practical problem that makes is difficult to translate the results presented below into an implementable policy rule. This is a problem which (except for special cases) also exists in a significant proportion of the monetary policy literature following the approach of Woodford (2003) so our approach is no especially limited in this respect.

A separate point regarding implementation (which is again common to the majority of the literature on optimal monetary policy) is that optimal policy is here being characterised as rule which is specified in terms of the rate of inflation and the rate of change in gap variables (in our case the distance from perfect risk sharing). There is an implicit assumption that the optimal policy rule has been in place for many periods and the objective of policy is to respond to stochastic shocks around an optimal (stochastic) steady state. But the policy problem that is often faced by policymakers is how to set policy in an environment where past policy may have been far from optimal. The main policy issue is therefore one of choosing an optimal path from a non-optimal initial point back to the optimal (stochastic) steady state. In this respect a targeting rule (such as (8)) which specifies policy in terms of the rate of inflation and the change in deviations from perfect risk sharing may be quite misleading as a guide to policy when the initial position of the economy is far from its optimal steady state. In such a situation the policy maker should be concerned about the level deviation from the perfect risk sharing - not the rate of divergence (as implied by (8)). This is an interesting question for further research, but an full analysis of this issue is well beyond the scope of this paper.

\section{Model Solution, Country Portfolios and Policy Op- timisation}

Our objective in this paper is to analyse optimal monetary policy in the above specified model. The key distinguishing feature of the above model, that sets it apart from much of the existing literature on optimal monetary policy in open economies, is that it allows for international trade in multiple assets.

Combining the analysis of optimal policy and endogenous portfolio choice presents some new technical challenges. These challenges arise because there is an interaction between policy choices and portfolio choice. Monetary policy affects the stochastic be- 
haviour of income and the hedging properties of assets and therefore affects optimal portfolio choice. In turn, the equilibrium portfolio affects consumption and labour supply choices and thus affects macroeconomic outcomes and welfare. Thus, in addition to the standard routes via which policy affects the macro economy, the optimal choice of monetary policy must take account of the welfare effects of policy that occur via the effects of policy on portfolio allocation. As will be demonstrated below, this mechanism turns out to play a key role. ${ }^{9}$

Our solution approach follows the recent portfolio literature based on Devereux and Sutherland (2011a) in computing equilibrium portfolios using a second order approximation to the portfolio selection equations for the home and foreign country in conjunction with a first order approximation to the home and foreign budget constraints and the vector of excess returns.

As already explained, we model monetary policy as a simple targeting rule (8). We optimise the choice of coefficient in the targeting rule by means of a grid search algorithm. Each grid point represents a different value for $\delta_{\mathcal{D}}$ in the targeting rule and for each grid point there is an equilibrium portfolio allocation and a corresponding general macroeconomic equilibrium and level of welfare. We use the Devereux and Sutherland (2011b) portfolio solution approach to evaluate the equilibrium portfolio at each grid point. This equilibrium portfolio is then used to compute macroeconomic equilibrium and evaluate welfare at each grid point.

In conducting this analysis it necessary to be mindful of orders of approximation. We approximate welfare up to second order. As is well-understood in the literature, this requires that the overall model must also be solved up to second-order accuracy. But note that, according to the principles outlined in Samuelson (1970), an order $n$ approximation of utility (in our case welfare) depends only on the order $n-2$ behaviour of portfolios. Thus, in computing a second order approximation of welfare, we only require the zero-order (or steady state) equilibrium portfolio. Hence the technique outlined in Devereux and Sutherland (2011a) for computing the zero-order portfolio is sufficient for our purposes. ${ }^{10}$

\footnotetext{
${ }^{9}$ In this paper we are making an assumption that policy choices are made in advance of trade in asset markets. This implies that equilibrium portfolios depend on the choice of monetary policy rule. In another paper, Senay and Sutherland (2013), we also emphasise how monetary policy can interact with portfolio choice. But in that earlier paper we analyse non-cooperative policy in a world where financial markets are complete. The interaction that occurs there is an explicitly distortionary effect that is quite different to the mechanism being analysed in this paper.

${ }^{10}$ Note, the fact that welfare is based on expected utility is crucial in allowing us to focus on the
} 
Discount factor

Elasticity of substitution: individual goods

Elasticity of labour supply

Risk aversion

Share of home goods in consumption basket

Elasticity of substitution: home and foreign goods

Share of labour in production

Calvo price setting

TFP shocks

Taste shocks

$$
\begin{aligned}
& \bar{\beta}=0.99, \eta=0.005 \\
& \lambda=6 \\
& 1 / \phi=0.5 \\
& \rho=2 \\
& \gamma=0.875 \\
& \theta=0.25-6.00 \\
& \mu=0.67 \\
& \kappa=0.75 \\
& \eta_{A}=0.95, \sigma_{A}=0.006 \\
& \eta_{\Psi}=0.9, \sigma_{\Psi}=0.01
\end{aligned}
$$

\section{Optimal Monetary Policy in the Basic Model}

The benchmark parameter values used in the following analysis are listed in Table 1. Many of these parameter values are taken directly from Corsetti et al (2010, 2018). The values of $\lambda$ (the elasticity of substitution between individual final goods) and $\mu$ (the Cobb-Douglas coefficient on labour in the production function of intermediate goods) are chosen to yield a steady state monopoly mark-up of $11 \%$ and share of capital in output of 0.33 . The implied steady state share of dividends in GDP is approximately 0.15. The Calvo parameter for price setting, $\kappa$, is chosen to imply an average period between price changes of 4 quarters. The values of $\phi$ (inverse labour elasticity) and $\rho$ (risk aversion) are consistent with the estimates of Smets and Wouters (2003, 2005, 2007). The parameters of the endogenous discount factor, $\bar{\beta}$ and $\eta$, are chosen to yield a steady state rate of return of approximately $4 \%$. The TFP and taste shock processes are based on Corsetti et al (2010, 2018) and Smets and Wouters (2003, 2005, 2007).

In this section we focus on optimal policy based on the simple policy rule given in (8).

zero-order portfolio. A second-order approximation of realised utility may include terms that depend on the first-order behaviour of portfolio holdings multiplied by the first-order realisation of asset return differentials. These terms, however, drop out when the expectations operator is applied and therefore do not enter the expression for the second-order approximation of expected utility. See Devereux and Sutherland (2010b) for a more detailed discussion of orders of approximation in the analysis of portfolios. 
This allows us to illustrate in detail the economic mechanism behind the effects we wish to emphasise. Given the simplified policy rule, the only policy parameter that needs to be determined is $\delta_{\mathcal{D}}$. It is therefore simple to investigate the effects of different values of $\delta_{\mathcal{D}}$ on welfare, portfolio allocation and the variances of key variables.

Table 2 presents some key results for a range of values of the international trade elasticity, $\theta$. For comparison, this table shows the results for the two-bond case together with the financial autarky and single-real-bond version of the model. For each value of $\theta$ and for each financial market structure the table shows the optimal value of $\delta_{\mathcal{D}}$, the welfare difference between optimal policy and strict inflation targeting, the standard deviations of a number of variables in the case of optimal policy and inflation targeting and (for the two-bond case) equilibrium portfolios for the case of optimal policy and inflation targeting. Welfare is measured in terms of the equivalent percentage of steady state consumption. Standard deviations are reported in percentage terms. And portfolio holdings are measured relative to steady state GDP. Given that, in this simple model, there are just two assets that can be traded internationally, it is possible to represent portfolio positions in terms of a single number. In this case we focus on the home country's portfolio position in the foreign nominal bond. As in Devereux and Sutherland (2011a), we compute the zero-order (i.e. steady state) portfolio holding. In the steady state it is assumed that net foreign assets are zero, so a positive holding of foreign bonds must be matched by an equivalent negative (external) holding of home bonds. ${ }^{11}$

First consider the autarky and single-bond cases. These two cases correspond to the financial market structures considered by Corsetti et al (2010, 2018). For both these cases, and for all the values of $\theta$ shown, the optimal value of $\delta_{\mathcal{D}}$ (derived numerically using the search procedure outlined above) differs from zero. This indicates a deviation from strict inflation targeting (which corresponds to $\delta_{\mathcal{D}}=0$ ). But notice that the difference between the welfare level yielded by optimal policy and the welfare level yielded by strict inflation targeting is very small for all values of $\theta$, except for $\theta=1 / 2$. The variance of the real exchange rate gap and the variance of PPI inflation are also only marginally

\footnotetext{
${ }^{11}$ Note that, for all values of $\theta$, gross portfolio positions are very large relative to steady state GDP. Portfolio positions of this magnitude are obviously very unrealistic. It is only for very few countries (usually tax havens) where external portfolio positions exceed 4 or 5 times GDP. It is not the purpose of this analysis to match the data on international portfolio positions. Such an exercise is likely to require consideration of transaction costs, informational asymmetries, and taxation and financial regulation issues which go well beyond the scope of the analysis in this paper. Note that throughout our analysis (again for the purposes of simplification) we also abstract from short selling constraints.
} 
Table 2: Results for the Benchmark Case

\begin{tabular}{|c|c|c|c|c|c|c|}
\hline Trade elasticity, $\theta$ & & 0.25 & 0.5 & 0.75 & 1.5 & 3 \\
\hline \multicolumn{7}{|l|}{ Two Bonds } \\
\hline Optimal Policy rule & $\delta_{\mathcal{D}}$ & 3.066 & 5.663 & -6.281 & -1.686 & -0.94 \\
\hline Welfare difference & & 0.0023 & 0.0020 & 0.0029 & 0.0036 & 0.0041 \\
\hline \multirow[t]{2}{*}{ Portfolio (bond holdings) } & (optimal) & -10.7 & -4.4 & 5.8 & 30.7 & 79.5 \\
\hline & (inf tar) & -16.2 & -8.4 & -0.6 & 22.8 & 69.6 \\
\hline St Dev PPI Inflation & (optimal) & 0.017 & 0.044 & 0.029 & 0.010 & 0.008 \\
\hline \multirow[t]{2}{*}{ St Dev Output gap } & (optimal) & 0.011 & 0.072 & 0.045 & 0.049 & 0.042 \\
\hline & (inf tar) & 0.014 & 0.080 & 0.119 & 0.184 & 0.237 \\
\hline \multirow[t]{2}{*}{ St Dev RER gap } & (optimal) & 1.29 & 0.90 & 0.61 & 0.27 & 0.10 \\
\hline & (inf tar) & 2.99 & 2.20 & 1.76 & 1.13 & 0.67 \\
\hline \multirow[t]{2}{*}{ St Dev $\mathcal{D}$} & (optimal) & 0.88 & 0.69 & 0.55 & 0.33 & 0.19 \\
\hline & (inf tar) & 2.04 & 1.74 & 1.59 & 1.39 & 1.27 \\
\hline \multicolumn{7}{|l|}{ Autarky } \\
\hline Policy rule & $\delta_{\mathcal{D}}$ & 0.017 & -0.085 & -0.010 & -0.003 & 0.00 \\
\hline Welfare difference & & 0.0003 & 0.0291 & 0.0000 & 0.0000 & 0.0000 \\
\hline St Dev PPI Inflation & (optimal) & 0.026 & 0.217 & 0.007 & 0.002 & 0.000 \\
\hline \multirow[t]{2}{*}{ St Dev RER gap } & (optimal) & 8.45 & 16.91 & 1.88 & 1.58 & 1.18 \\
\hline & (inf tar) & 8.52 & 18.91 & 1.90 & 1.58 & 1.18 \\
\hline \multicolumn{7}{|l|}{ Single Bond } \\
\hline Policy rule & $\delta_{\mathcal{D}}$ & 0.124 & -0.394 & -0.018 & 0.027 & 0.037 \\
\hline Welfare difference & & 0.0008 & 0.0430 & 0.0000 & 0.0000 & 0.0000 \\
\hline St Dev PPI Inflation & (optimal) & 0.043 & 0.287 & 0.001 & 0.003 & 0.005 \\
\hline \multirow[t]{2}{*}{ St Dev RER gap } & (optimal) & 12.67 & 22.18 & 1.84 & 1.57 & 1.13 \\
\hline & (inf tar) & 12.86 & 24.65 & 1.84 & 1.57 & 1.13 \\
\hline
\end{tabular}

Note: For each $\theta$ and financial structure the table shows the optimal value of $\delta_{\mathcal{D}}$, the welfare difference between optimal policy and inflation targeting, standard deviations for optimal policy and inflation targeting and (for the two-bond case) equilibrium portfolios for optimal policy and inflation targeting. Welfare is measured in terms of the equivalent percentage of steady-state consumption. Standard deviations are measured in percentages. Portfolio holdings are measured relative to steady state GDP. 
different between the optimal policy and strict inflation targeting equilibria for all values of $\theta$, except for $\theta=1 / 2$.

These results broadly match the results emphasised by Corsetti et al (2010, 2018) who find that the differences between the optimal rule and inflation targeting are likely to be very small except for low values of $\theta$. The results in Table 2 go somewhat further than Corsetti et al $(2010,2018)$ by showing that non-trivial differences between optimal policy and inflation targeting are not strictly associated with low values of $\theta$. It is more correct to say that they arise at values of $\theta$ close to $1 / 2$. The significance of $\theta=1 / 2$ is easily explained. Given the values of other parameters (in particular the value of $\rho$ ) at $\theta=1 / 2$ the income and substitution effects of the terms of trade on the trade balance almost cancel each other out. It follows therefore that at $\theta=1 / 2$ the trade balance is very insensitive to the terms of trade. In this case, the absence of financial trade (or the highly restricted nature of financial trade) has significant implications for welfare because the terms of trade and real exchange rate become very sensitive to shocks (as can be seen in Table 2). ${ }^{12}$ There is therefore a strong incentive for the policymaker to deviate from inflation targeting. At other values of $\theta$ (either above or below $1 / 2$ ) the trade balance is more sensitive to changes in the terms of trade so the terms of trade and real exchange rate are less volatile and the absence of financial trade (or the limited nature of financial trade) is less significant for welfare. In this case the incentive to deviate from inflation targeting is much reduced.

The general message from Table 2 is that our basic model reproduces the results of Corsetti et al $(2010,2018)$ for the autarky and single-bond cases, i.e. optimal policy does deviate from inflation targeting, but this appears to be quantitatively important only for a restricted range of values of $\theta$ (i.e. close to $1 / 2) .{ }^{13}$

\footnotetext{
${ }^{12}$ When the trade balance is relatively insensitive to changes in the terms of trade and there is no financial market (i.e. there is financial autarky), any shock which causes a change in the trade balance must cause a large change in the terms of trade in order to bring the trade balance back to zero. In turn, this causes large fluctuations in consumption and work effort. So, in the vicinity of $\theta=1 / 2$, consumption and work effort are highly volatile. This creates a strong incentive for the policymaker to stabilise the terms of trade and real exchange rate. This effect is less acute, but still present, when there is trade in a single bond. See Bodenstein (2010) and Rabitsch (2012) for further discussion of how a number of key welfare and equilibrium results can be reversed at particularly low values of the trade elasticity in models similar to the one analysed here.

${ }^{13}$ Note that the standard deviations of the real exchange rate gap and the output gap (and other variables) are all quite sensitive to the degree of persistence of TFP and taste shocks. However, the persistence of shocks has no significant implications for the optimal policy rule or the difference between
} 
Now consider the two-bond case. The results in Table 2 show that again there is a deviation between optimal policy and strict inflation targeting. But now the pattern of results is quite different to that found in the autarky and single-bond cases. In the twobond case the welfare difference between optimal policy and inflation targeting is now non-trivial for all values of $\theta$. There are also relatively large differences between optimal policy and inflation targeting in terms of the variances of the real exchange rate and the output gap. In particular, optimal policy implies very significant stabilisation of the real exchange rate gap compared to strict inflation targeting, regardless of the value $\theta .{ }^{14}$

It is clear, therefore, that there is a significant qualitative and quantitative difference between the two-bond case and the other financial market structures shown in Table 2 . This is somewhat surprising. In terms of the degree of market incompleteness it would be natural to assume that the two-bond case is closer to complete markets than the autarky and single-bond cases. One would therefore naturally predict that the optimal policy rule in the two-bond case would be closer to the optimal policy rule in the complete market case (i.e. strict inflation targeting) than it is in the autarky and single-bond cases. However, the results in Table 2 contradict this intuition. It appears from the results in Table 2 that trade in two bonds pushes optimal policy further away from strict inflation targeting (at least for values of $\theta$ different from $1 / 2$ ) than in the autarky and single-bond case. What is causing this counter-intuitive result?

The key to understanding the answer to this question is to consider in detail the role of portfolio allocation. In the autarky and single-bond cases there is, by definition, no portfolio decision for agents to make. In the autarky case there are no traded assets so there is no portfolio. In the single-bond case there is only one traded asset so portfolio composition is fixed. But in the two-bond case there are two traded assets so there is a

optimal policy and inflation targeting equilibria for either the autarky or single-bond cases.

${ }^{14}$ Notice in Table 2 that, for the two-bond case, the divergence between optimal policy and inflation targeting is at its smallest at $\theta=0.5$ and rises for values of $\theta$ away from 0.5 . This contrasts with the autarky and single-bond cases where the divergence is at it largest at $\theta=0.5$. This contrast is again due to the fact that the income and substitution effects of terms of trade changes almost perfectly cancel in the vicinity of $\theta \rho=1$. This in turn implies that the trade balance is relatively insensitive to changes in the terms of trade generated by TFP shocks. Another way to view this is that (as shown by Cole and Obstfeld (1991)), in the vicinity of $\theta \rho=1$, movements in the terms of trade provide a significant degree of hedging against TFP shocks. This allows portfolio allocation across the two bonds to be more focused on hedging of taste shocks. With the combination of the terms of trade movements and bond portfolios providing significant risk sharing in the vicinity of $\theta \rho=1$, there is less need for optimal monetary policy to deviate from inflation stabilisation. 
portfolio allocation decision. The existence of the portfolio allocation decision gives the policymaker a qualitatively different channel by which to influence the equilibrium degree of risk sharing and this new channel has a qualitatively and quantitatively important effect on the optimal policy rule. In the two-bond case the policymaker can implicitly use monetary policy to alter the risk sharing properties of the two bonds, and can therefore influence the equilibrium portfolio, in such a way that the equilibrium portfolio provides a significantly higher degree of risk sharing compared to an inflation targeting equilibrium. This can be a powerful incentive for the policymaker to deviate from strict inflation targeting. This portfolio allocation incentive, by definition, does not exist in the autarky or single-bond cases and this explains the significant differences between the two-bond case and the autarky and single-bond cases.

This process is illustrated in more detail in Figure 1. This figure is based on the benchmark parameter set given in Table 1 with the international trade elasticity, $\theta$, set equal to 1.5. It therefore corresponds to one of the cases reported in Table 2. So it can be noted from Table 2 that the optimal value of $\delta_{\mathcal{D}}$ is approximately -1.686 . Panel (a) in Figure 1 plots welfare against $\delta_{\mathcal{D}}$ and shows that welfare at the optimal value of $\delta_{\mathcal{D}}$ is approximately $0.0036 \%$ above welfare at strict inflation targeting $\left(\delta_{\mathcal{D}}=0\right)$ (which again corresponds to the number reported in Table 2). ${ }^{15}$ Panel (b) shows the standard deviation of PPI inflation at the optimal value of $\delta_{\mathcal{D}}$ is approximately $0.01 \%$ while Panel (c) shows that the standard deviation of $\mathcal{D}$ is reduced by optimal policy by a factor of 4 when compared to strict inflation targeting (i.e. from $1.39 \%$ to $0.33 \%$ ). Panel (c) also shows that optimal policy implies a very significant reduction in the volatility of the real exchange rate gap compared to strict inflation targeting (i.e. from $1.13 \%$ for strict inflation targeting to $0.27 \%$ for optimal policy).

The main mechanism behind these effects is illustrated in relation to portfolio allocations and asset returns in Panels (d) and (e) of Figure 1. Panel (d) shows how equilibrium portfolio allocation depends on the choice of the parameter $\delta_{\mathcal{D}}$. Panel $(\mathrm{d})$ shows that this portfolio position rises from approximately 23 times steady state GDP at $\delta_{\mathcal{D}}=0$ (strict inflation targeting) to approximately 31 times steady state GDP at $\delta_{\mathcal{D}}=-1.686$ (optimal policy), so monetary policy has a significant impact on portfolio holdings. This is clearly an important part of the mechanism which allows optimal policy to reduce deviations from perfect risk sharing.

\footnotetext{
${ }^{15}$ Where welfare is measured as a percentage of steady state equivalent consumption. In Figure 1 Panel (a) this is normalised to be zero at inflation targeting.
} 
Figure 1: Portfolio Allocation and the Monetary Policy Rule

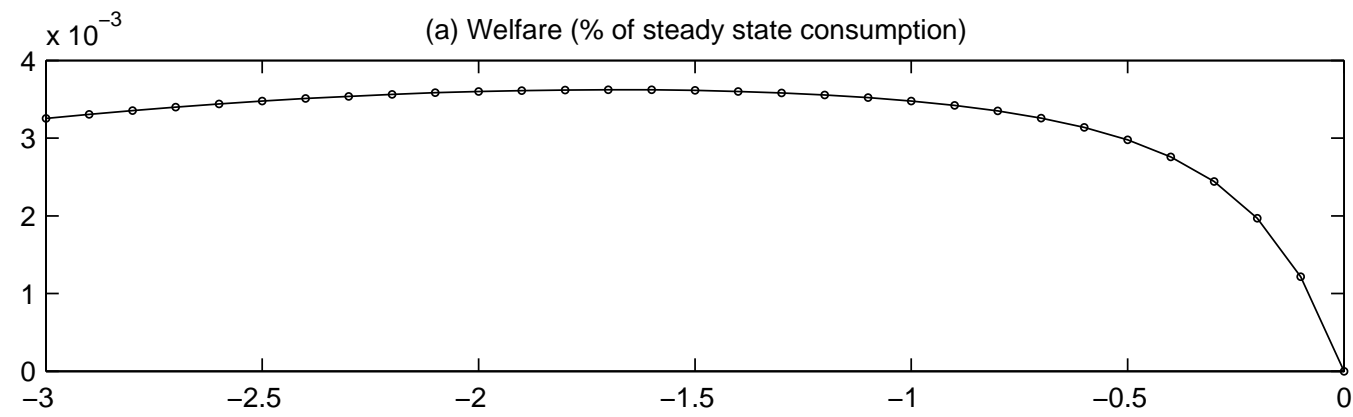

(b) Standard deviation of PPI inflation (\%)

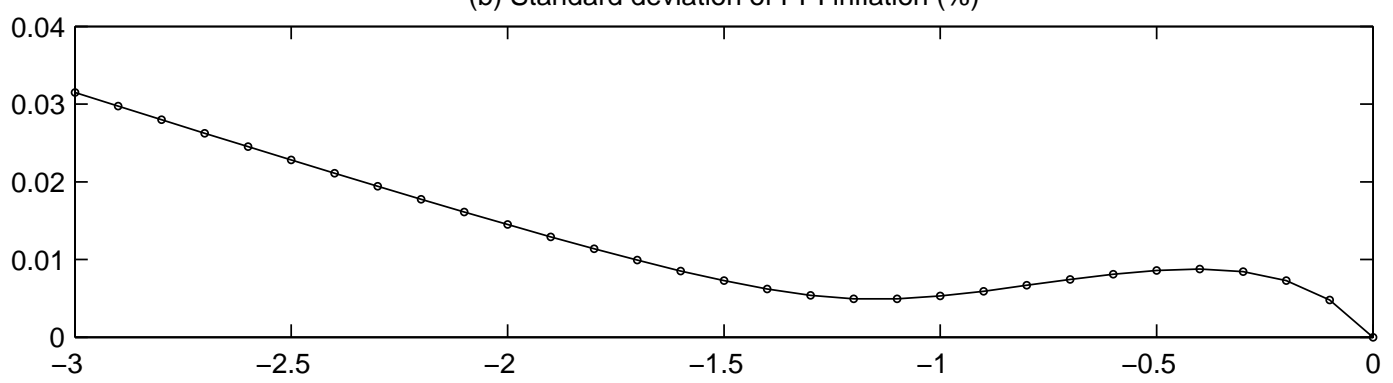

(c) Standard deviations of $\mathrm{D}$ and the real exchange rate gap (\%)

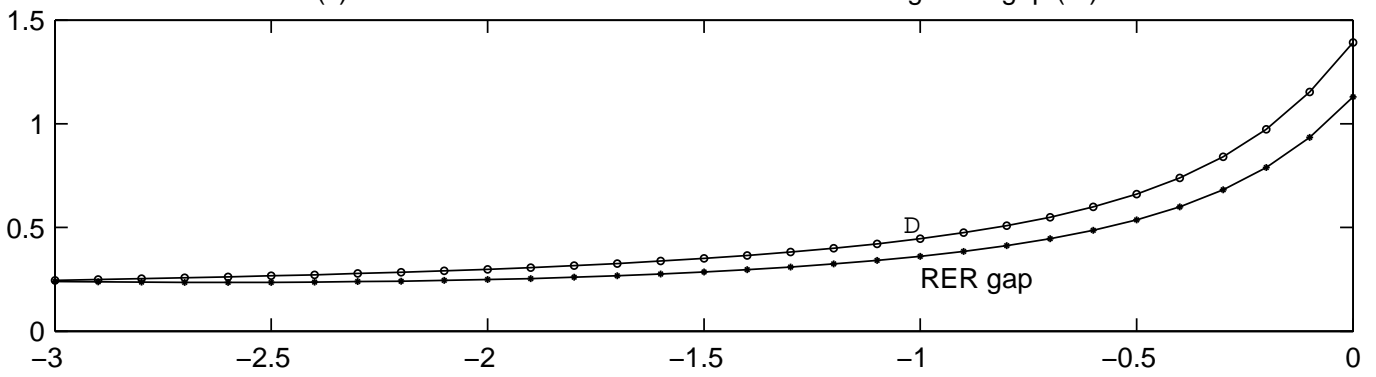

(d) Shadow bond holdings (relative to steady state GDP)

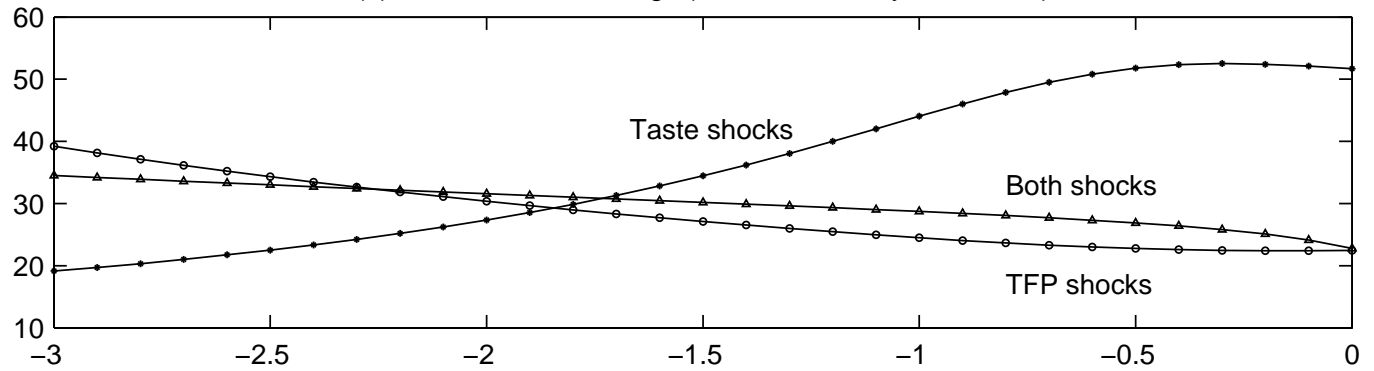

(e) Impact effect of shocks on the rate of return differntial (\%)

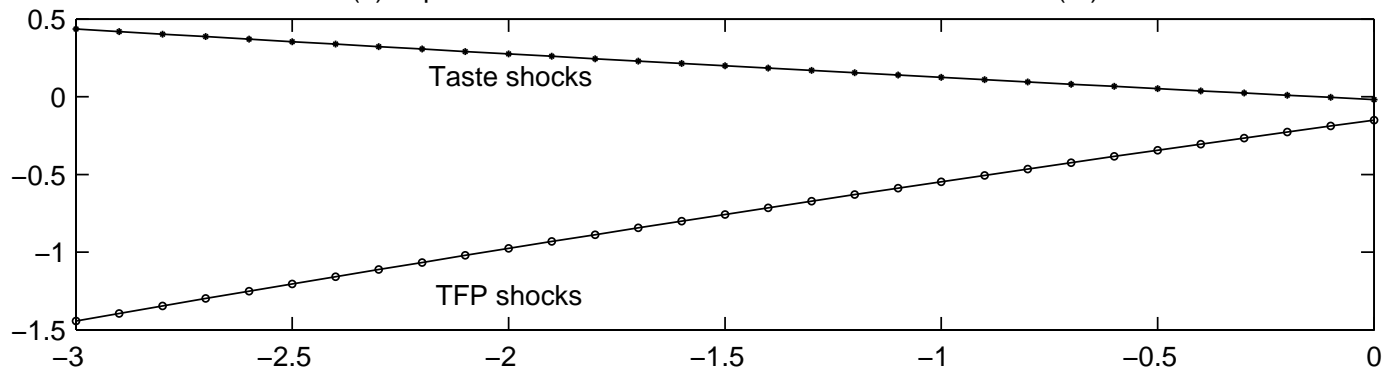

The policy parameter, $\delta_{D}$, is plotted on the horizontal axis in each panel. 
But the role played by portfolio allocation can be understood more clearly if one considers the nature of imperfect risk sharing in this simple model. There are two independent sources of risk faced by households - TFP shocks and taste shocks. But there is only one degree of freedom in portfolio choices to allow hedging against these two sources of risk. The equilibrium portfolio is therefore a compromise between hedging the two different sources of risk. The degree of compromise can be illustrated by comparing two alternative 'shadow worlds' - one where there are only TFP shocks and one where there are only taste shocks. In each of these worlds there is a 'shadow portfolio allocation' which maximises welfare. ${ }^{16}$ The divergence between these two alternative shadow portfolio allocations is a measure of the conflict between hedging the two sources of shocks. So, if the shadow portfolio allocations are very different, one can say that there is a significant 'hedging conflict' in the choice of a portfolio designed to hedge both shocks simultaneously, i.e. the compromise portfolio is likely to offer limited hedging against one or other (or both) shocks. While, if the shadow portfolios are very similar, one can say that the 'hedging conflict' is less severe - i.e. a compromise portfolio is likely to be a good hedge against both shocks.

Panel (d) illustrates how these two shadow portfolio allocations depend on the policy parameter $\delta_{\mathcal{D}}$. In particular, these plots show that the degree of divergence between the two shadow portfolio allocations, and thus the degree of conflict between hedging the two sources of shocks, depends on $\delta_{\mathcal{D}}$. Panel (d) shows how the policy maker can ease the conflict between hedging TFP shocks and hedging taste shocks by making an appropriate choice of the policy parameter $\delta_{\mathcal{D}}$. It is apparent from Panel $(\mathrm{d})$ that the optimal choice of $\delta_{\mathcal{D}}\left(\delta_{\mathcal{D}}=-1.686\right)$ significantly reduces the divergence between the shadow portfolio allocations and thus allows the equilibrium portfolio allocation to become simultaneously a good hedge against both sources of risk. It is this that allows optimal policy to generate

\footnotetext{
${ }^{16}$ Note that, for any single shock or combination of shocks, the welfare maximising portfolio is not necessarily equal to the market equilibrium portfolio (as yielded by the Devereux and Sutherland (2011a) approach). This is because the endogenous discount factor defined in (2) implies an externality in portfolio selection. Individual households treat aggregate consumption as exogenous when selecting their portfolio position while a welfare maximising policymaker would internalise this effect. The shadow portfolios shown in the figure are based on maximising welfare and therefore differ from the portfolios that would be selected by households in the presence of each shock. The welfare maximising shadow portfolios are relevant here because, in this exercise, we are illustrating the incentives faced by the policymaker in choosing the policy rule. The shadow portfolios are computed using a search algorithm that maximises welfare (as measured by (7)) in the presence of each individual source of shock and for each value of the policy parameter, $\delta_{\mathcal{D}}$.
} 
a significant reduction in deviations for perfect risk sharing. ${ }^{17}$

Note, of course, that any deviation of policy from strict inflation targeting generates inflation volatility, which (given sticky nominal prices) has a negative effect on welfare, so optimal policy is a compromise between inflation volatility and deviations from risk sharing.

Panel (d) illustrates the impact of policy on portfolio and shadow portfolio allocations. But further insight into the effects of policy on portfolio allocations can be found in Panel (e). This panel shows the impact effect of each shock on the return differential between the two bonds. The size and sign of these effects are key determinants of the equilibrium and shadow portfolio allocations. Panel (e) shows that the policy parameter has a significant influence on the impact effects of shocks on the return differential so it is evident that this link is an important part of the mechanism that allows monetary policy to affect portfolio allocations. ${ }^{18}$

Figure 1 shows clearly how portfolio allocation plays an important role in the policy transmission mechanism. In particular, these results show that policy has a potentially important role in easing the hedging conflict that arises when there are more sources of risk than degrees of freedom in portfolio allocation. However, it should be clear from this explanation, that this mechanism can only be important if a hedging conflict exists in the first place. The example illustrated in our simple benchmark model is one where TFP shocks and taste shocks create a significant hedging conflict. We will show below that these two sources of shocks continue to create a hedging conflict in a more general model. But we also show that other combinations of shocks may not give rise to such a significant hedging conflict. In these cases, the optimal policy rule is much closer to strict inflation

\footnotetext{
${ }^{17}$ Note that the externality contained within the endogenous discount factors (which generates a difference between the equilibrium portfolio allocation and the welfare maximising portfolio allocation) implies that it is not possible for policy to achieve perfect risk sharing by choice of $\delta_{\mathcal{D}}$. Note also that this same externality also implies that the market equilibrium portfolio will not yield full risk sharing even in a case where there are sufficient assets to span the space of shocks. In principle in the two-bond model this implies that there would be a policy trade-off between inflation stabilisation and risk sharing even if there is only one source of shocks (and thus no hedging conflict). Numerical experiments with the basic model show that this effect is quantitively extremely small and therefore has no significant quantitive implications for the main focus of analysis in this paper.

${ }^{18}$ The hedging properties of a portfolio position depend on how the return differential (i.e. the difference between the return on the home bond and the foreign bond) responds on impact to the two shocks. Note, however, that there are a number of interacting factors which determine the equilibrium and shadow portfolios, so it is not possible to draw a simple link between the effects of the policy parameter on return differentials in Panel (e) and the shadow portfolio allocations shown in Panel (d).
} 
targeting - so it will become clear that the particular combination of shocks chosen in our benchmark model is a critical factor in the results illustrated in Table 2 and Figure 1.

\section{A More General Model}

In this section we generalise the basic model in a number of directions. We add four additional sources of risk: labour supply shocks, news shocks, government spending shocks and price mark-up shocks. We add more assets and consider a more general policy rule. We also consider the effects of local currency pricing. Note that as in the basic model, the number of assets in the extended model is insufficient to provide hedging against the full range of shocks, so financial markets continue to be incomplete.

The household utility function is modified as follows

$$
U_{t}=E_{t} \sum_{i=0}^{\infty} \beta_{i}\left\{\Psi_{t+i} \frac{C_{t+i}^{1-\rho}(z)}{1-\rho}-\Delta_{t+i} \frac{H_{t+i}^{1+\phi}(z)}{1+\phi}\right\}
$$

where $\Delta_{t}$ are stochastic preference shocks which affect labour supply. We assume $\Delta_{t}=$ $\bar{\Delta} \exp \left(\hat{\Delta}_{t}\right)$ where $\hat{\Delta}_{t}=\eta_{\Delta} \hat{\Delta}_{t-1}+\varepsilon_{\Delta, t}, 0 \leq \eta_{\Delta}<1$ and $\varepsilon_{\Delta, t}$ is a zero-mean normally distributed i.i.d. shock with $\operatorname{Var}\left[\varepsilon_{\Delta}\right]=\sigma_{\Delta}^{2}$.

Total factor productivity, $A_{t}$, is now defined as follows:

$$
A_{t}=U_{t}-V_{t}
$$

where

$$
U_{t}=\eta_{u} U_{t-1}+\varepsilon_{u, t}+\varepsilon_{\nu, t} \quad V_{t}=\eta_{\nu} V_{t-1}+\varepsilon_{\nu, t}
$$

where $\eta_{u}>\eta_{\nu}$ and $\varepsilon_{\nu, t}$ and $\varepsilon_{u, t}$ are zero mean normally distributed i.i.d. shocks with $\operatorname{Var}\left[\varepsilon_{\nu}\right]=\sigma_{\nu}^{2}$ and $\operatorname{Var}\left[\varepsilon_{u}\right]=\sigma_{u}^{2}$. This structure captures the concept of news shocks as in Beaudry and Portier (2006). ${ }^{19}$

We add a government sector where total government expenditure is assumed to be exogenous and subject to stochastic shocks. In particular we assume that $G_{t}=\bar{G} \exp \left(\hat{G}_{t}\right)$ is government spending where $\hat{G}_{t}=\eta_{G} \hat{G}_{t-1}+\varepsilon_{G, t}, 0 \leq \eta_{G}<1$ and $\varepsilon_{G, t}$ is a zero-mean normally distributed i.i.d. shock with $\operatorname{Var}\left[\varepsilon_{G}\right]=\sigma_{G}^{2}$. All government spending is assumed

\footnotetext{
${ }^{19}$ In the absence of shocks to $V$ this structure yields TFP shocks of exactly the same form as in the simple model, so $\varepsilon_{u, t}$ captures contemporaneous innovations in TFP. News shocks on the other hand are represented by $\varepsilon_{v, t}$. So, for instance, given the assumption that $\eta_{u}>\eta_{v}$, a positive realisation of $\varepsilon_{v, t}$ raises the expected future time path of TFP for $t+1$ onwards (i.e. $\varepsilon_{v, t}$ contains news about future TFP) but has no impact on TFP in period $t$.
} 
to be financed via lump sum taxes on households, $T_{D}$, and firms, $T_{C}$. The government budget constraint is $P_{G, t} G_{t}=P_{t} T_{D, t}+P_{t} T_{C, t}$ where it is assumed that $P_{t} T_{D}=(1-\varrho) P_{G, t} G$ and $P_{t} T_{C}=\varrho P_{G, t} G$ where $\varrho$ is a fixed parameter which determines the share of profit taxes in the overall tax take. $P_{G, t}$ is the price index of government purchased goods. It is assumed that government spending is on domestically produced goods so $P_{G, t}=P_{H, H, t}$. The household budget constraint is modified to include $T_{D}$.

Monopoly power in the final goods sector implies that final goods prices are subject to a mark-up given by $v_{t}=\lambda_{t} /\left(\lambda_{t}-1\right)$. In the benchmark model the mark-up is assumed to be fixed. In the extended model the mark-up is assumed to be subject to stochastic shocks such that $v_{t}=\bar{v} \exp \left(\hat{v}_{t}\right)$ where $\hat{v}_{t}=\eta_{v} \hat{v}_{t-1}+\varepsilon_{v, t}, 0 \leq \eta_{v}<1$ and $\varepsilon_{v, t}$ is a zero-mean normally distributed i.i.d. shock with $\operatorname{Var}\left[\varepsilon_{v}\right]=\sigma_{v}^{2}$.

In the extended analysis of the model we allow for local currency pricing (LCP). In the LCP case final good firm $z$ chooses $p_{H, H, t}(z)$ in home currency and $p_{H, F, t}^{*}(z)$ in foreign currency to maximize (6) where $p_{H, F, t}(z)$ is replaced by $p_{H, F, t}^{*}(z) S_{t+i}$.

The extended model allows for trade in equities. Home equities represent a claim on aggregate profits of all firms in the home final and intermediate sectors. The real payoff to a unit of the home equity purchased in period $t$ is defined to be $\Pi_{t+1}+Z_{E, t+1}$, where $Z_{E, t+1}$ is the real price of home equity and $\Pi_{t+1}$ is real aggregate profits. Thus the gross real rate of return on the home equity is $r_{E, t+1}=\left(\Pi_{t+1}+Z_{E, t+1}\right) / Z_{E, t}$. Foreign equities are similarly defined. Total dividends aggregated across al intermediate and final goods firms are given by

$$
\Pi_{t}=\frac{P_{Y, t}}{P_{t}} Y_{t}-\frac{w_{t}}{P_{t}} L_{t}-T_{C}
$$

The benchmark parameter values assumed for the additional parameters in the extended model are shown in Table 3. Again these parameter values are based on Corsetti et al (2010, 2018) and Smets and Wouters (2003, 2005, 2007).

\subsection{A general policy rule}

We extend the simple policy rule used in the simple model to include a number of terms which capture additional welfare gaps. The generalised rule takes the following form:

$$
\begin{gathered}
\delta_{\pi}\left(\hat{P}_{Y, t}-\hat{P}_{Y, t-1}\right)+\left(1-\delta_{\pi}\right)\left(\hat{P}_{t}-\hat{P}_{t-1}\right)+\delta_{\mathcal{D}}\left(\mathcal{D}_{t}-\mathcal{D}_{t-1}\right)+\delta_{Y}\left(Y_{G, t}-Y_{G, t-1}\right) \\
+\delta_{\tau}\left(\tau_{G, t}-\tau_{G, t-1}\right)+\delta_{\mathcal{L}}\left(\mathcal{L}_{t}-\mathcal{L}_{t-1}\right)=0
\end{gathered}
$$




$\begin{array}{ll}\text { Share of government spending in output } & g=0.2 \\ \text { Share of profit taxes in total taxes } & \varrho=0.15 \\ \text { TFP and news shocks } & \eta_{\nu}=0.9, \sigma_{\nu}=0.019 \\ & \eta_{u}=0.95, \sigma_{u}=0.006 \\ \text { Labour supply shocks } & \eta_{\Delta}=0.9, \sigma_{\Delta}=0.025 \\ \text { Mark-up shocks } & \eta_{v}=0.0, \sigma_{v}=0.0015 \\ \text { Government spending shocks } & \eta_{G}=0.9, \sigma_{G}=0.003\end{array}$

where $\mathcal{D}$ and $\hat{P}_{Y, t}-\hat{P}_{Y, t-1}$ again capture PPI inflation and deviations from perfect risk sharing. The additional terms are based on $Y_{G}, \tau_{G}$ and $\mathcal{L}$. These are defined as follows

$$
\begin{gathered}
Y_{G}=\hat{Y}-\hat{Y}^{f b} \\
\tau_{G}=\hat{\tau}-\hat{\tau}^{f b} \\
\mathcal{L}=\hat{P}_{H, H}-\hat{S}-\hat{P}_{H, F}^{*}
\end{gathered}
$$

where the superscript $f b$ indicates the first best value of a variable and $\tau$ is the terms of trade. Thus $Y_{G}$ is a measure of the output gap, $\tau_{G}$ is a measure of the terms of trade gap and $\mathcal{L}$ is a measure of the deviation from the law of one price. There is an analogous targeting rule for the foreign economy.

The targeting rule in (10) now contains six terms. The first two terms represent a weighted average of producer price (PPI) and consumer price (CPI) inflation. This captures the result shown by Corsetti et al $(2010,2018)$ that, for general parameter combinations, in the case of LCP the welfare-relevant measure of inflation is effectively a weighted average of PPI and CPI inflation.

The fourth term in (10) measures the welfare-relevant output gap. The role of the output gap in optimal targeting rules in New Keynesian models is well-known and needs no further explanation.

The fifth term in the targeting rule measures the welfare-relevant terms-of-trade gap. As Corsetti et al $(2010,2018)$ explain in detail, in an open economy, because there are different baskets of goods produced in different countries, shocks may have distortionary effects on the relative price of these different baskets. These distortions are welfare 
reducing in the same way as the within-country price distortions generated by inflation are welfare reducing. The terms of trade gap therefore plays the same role in the monetary policy rule as the CPI and PPI inflation terms.

The final term in the targeting rule captures the welfare reducing effects of deviations from the law of one price. Such deviations are a direct consequence of (and only arise from) local currency pricing. In a similar way to the price distortions caused by staggered pricing, deviations from the law of one price are a form of price distortion which potentially requires a monetary policy response.

Note that policy rule (10) contains strict CPI and PPI inflation targeting as special cases. Strict CPI inflation targeting is given by $\delta_{\pi}=\delta_{Y}=\delta_{\tau}=\delta_{\mathcal{D}}=\delta_{\mathcal{L}}=0$ and strict PPI inflation targeting is given by $\delta_{\pi}=1, \delta_{Y}=\delta_{\tau}=\delta_{\mathcal{D}}=\delta_{\mathcal{L}}=0$.

Given the generalised rule, there are now five policy coefficients to be chosen by the policymaker. Our policy optimisation problem now involves a grid search across these five coefficients, i.e. $\delta_{\pi}, \delta_{Y}, \delta_{\tau}, \delta_{\mathcal{D}}$ and $\delta_{\mathcal{L}}$, in order to identify the parameter combination which maximises the unconditional expectation of period welfare (as defined in (7)).

It should be noted that, while this rule is a significant generalisation of the simple ruled used in our basic analysis, we do not claim that this methodology necessarily computes fully optimal policy for our model. Our optimal rule is simply the optimal rule within the restricted class of rules defined by (10).

\subsection{Optimal policy in the general model: PCP and LCP}

Results relating to the generalised model are presented in Tables 4 and 5 . Table 4 shows the PCP case and Table 5 shows the LCP case. Both tables show results for a range of values of the international trade elasticity, $\theta$, from 0.25 to $3 .^{20}$

Tables 4 and 5 report the coefficients of the optimal policy rule. It is clear that, as in

\footnotetext{
${ }^{20}$ As before, welfare is measured in terms of the equivalent percentage of steady state consumption and standard deviations are measured in percentage terms. Portfolio holdings are measured relative to steady state GDP. In a symmetric equilibrium (with zero net foreign assets in the steady state) a positive holding of foreign bonds is matched by a negative (external) position in home bonds and a positive holding of foreign equities is matched by a negative (external) holding on home equities. Hence the portfolio position can be summarised by home holdings of foreign bonds and home holdings of foreign equities. The foreign country portfolio is the mirror image of the home portfolio. Note that in the LCP case we compare optimal policy to CPI inflation targeting. Engel (2011) shows that, with LCP and perfect risk sharing, strict CPI inflation targeting is the optimal policy, so CPI inflation targeting is the natural benchmark for comparison in the LCP case in Table 5.
} 
Table 4: General model: PCP

\begin{tabular}{|c|c|c|c|c|c|c|}
\hline Trade elasticity, $\theta$ & & 0.25 & 0.5 & 0.75 & 1.5 & 3 \\
\hline \multirow[t]{5}{*}{ Policy rule } & $\delta_{Y}$ & 0.129 & 0.129 & 0.129 & 0.129 & 0.129 \\
\hline & $\delta_{\tau}$ & -0.021 & -0.068 & -0.204 & -0.007 & -0.003 \\
\hline & $\delta_{\mathcal{D}}$ & 0.584 & -0.635 & -0.770 & -1.020 & -0.542 \\
\hline & $\delta_{\mathcal{L}}$ & 0 & 0 & 0 & 0 & 0 \\
\hline & $\delta_{\pi}$ & 1.002 & 0.996 & 0.997 & 0.998 & 0.998 \\
\hline Welfare difference & & 0.0025 & 0.0030 & 0.0033 & 0.0038 & 0.0043 \\
\hline \multirow{2}{*}{ Portfolio (optimal) } & (bonds) & -23.0 & -42.7 & -33.3 & 23.8 & 68.4 \\
\hline & (equities) & 15.2 & 50.1 & 53.5 & 5.8 & -4.5 \\
\hline \multirow{2}{*}{ (inf tar) } & (bonds) & -14.4 & -7.3 & -0.2 & 21.1 & 63.7 \\
\hline & (equities) & 0.3 & 0.3 & 0.3 & 0.3 & 0.3 \\
\hline St Dev PPI Inflation & (optimal) & 0.0065 & 0.0082 & 0.0104 & 0.0074 & 0.0043 \\
\hline \multirow[t]{2}{*}{ St Dev Output gap } & (optimal) & 0.019 & 0.060 & 0.080 & 0.095 & 0.089 \\
\hline & (inf tar) & 0.028 & 0.093 & 0.134 & 0.196 & 0.245 \\
\hline \multirow[t]{2}{*}{ St Dev RER gap } & (optimal) & 2.68 & 1.77 & 1.28 & 0.64 & 0.27 \\
\hline & (inf tar) & 3.83 & 2.75 & 2.16 & 1.32 & 0.76 \\
\hline
\end{tabular}


Table 5: General model: LCP

\begin{tabular}{|c|c|c|c|c|c|c|}
\hline Trade elasticity, $\theta$ & & 0.25 & 0.5 & 0.75 & 1.5 & 3 \\
\hline \multirow[t]{5}{*}{ Policy rule } & $\delta_{Y}$ & 0.136 & 2.025 & 0.188 & 0.138 & 0.127 \\
\hline & $\delta_{\tau}$ & -0.965 & -0.181 & -0.316 & -0.299 & -0.201 \\
\hline & $\delta_{\mathcal{D}}$ & -0.143 & -1.829 & -2.029 & -1.099 & -1.626 \\
\hline & $\delta_{\mathcal{L}}$ & 1.912 & 0.358 & 0.535 & 0.452 & 0.262 \\
\hline & $\delta_{\pi}$ & 0.311 & 0.334 & 0.352 & 0.332 & 0.334 \\
\hline Welfare difference & & 0.0026 & 0.0029 & 0.0031 & 0.0034 & 0.0037 \\
\hline \multirow{4}{*}{ Portfolio (optimal) } & (bonds) & 45.2 & 36.4 & 23.2 & 41.3 & 66.0 \\
\hline & (equities) & -54.7 & -42.0 & -20.4 & -24.3 & -72.3 \\
\hline & (bonds) & 28.9 & 29.7 & 29.8 & 32.9 & 49.3 \\
\hline & (equities) & -53.4 & -51.3 & -47.3 & -25.2 & -64.2 \\
\hline St Dev CPI Inflation & (optimal) & 0.053 & 0.048 & 0.043 & 0.029 & 0.020 \\
\hline \multirow[t]{2}{*}{ St Dev Output gap } & (optimal) & 0.037 & 0.102 & 0.145 & 0.208 & 0.240 \\
\hline & (inf tar) & 0.076 & 0.148 & 0.198 & 0.275 & 0.328 \\
\hline \multirow[t]{2}{*}{ St Dev RER gap } & (optimal) & 2.81 & 2.02 & 1.68 & 1.43 & 1.40 \\
\hline & (inf tar) & 3.67 & 2.69 & 2.20 & 1.65 & 1.42 \\
\hline
\end{tabular}

Note: For each $\theta$ the table shows the optimal policy rule coefficients, the welfare difference between optimal policy and inflation targeting, standard deviations and equilibrium portfolios for optimal policy and inflation targeting. Welfare is measured in terms of the equivalent percentage of steady-state consumption. Standard deviations are measured in percentages. Portfolio holdings are measured relative to steady state GDP. 
the case of the simple model considered above, optimal policy implies quite a significant departure from inflation targeting in terms of the policy rule coefficients. Recall that strict PPI inflation targeting implies $\delta_{\pi}=1, \delta_{Y}=\delta_{\tau}=\delta_{\mathcal{D}}=\delta_{\mathcal{L}}=0$ and strict CPI inflation targeting implies $\delta_{\pi}=\delta_{Y}=\delta_{\tau}=\delta_{\mathcal{D}}=\delta_{\mathcal{L}}=0$. Tables 4 and 5 show that optimal policy implies relatively large values (in absolute terms) for the coefficient on the risk sharing gap, $\delta_{\mathcal{D}}$, so as emphasised in the context of the simplified model, optimal policy requires a strong response to the departures from full risk sharing that arise because of the incomplete market structure.

Tables 4 and 5 show the difference in welfare between optimal policy and a policy of inflation targeting. This difference is of the same order of magnitude as in the simple model. Notice that, contrary to the argument of Corsetti et al (2010, 2018) there does not appear to be a significant difference between the PCP and LCP cases in terms of the size of the welfare benefit of optimal policy. ${ }^{21}$

The lower half of Tables 4 and 5 show the implications of optimal policy and inflation targeting for the volatility of a number of variables. As emphasised in the context of the simple model, optimal policy implies quite significant stabilisation of the output gap and the real exchange rate gap relative to strict inflation targeting. Again this is true in both the PCP and LCP cases.

The cases analysed in Tables 4 and 5 are based on trade in both equities and bonds. It is useful to compare the results yielded by the two-bond-two-equity case to those yielded by other financial market structures. To do this we concentrate on the impact of optimal policy on the volatility of the real exchange rate and we focus on the PCP case. This is sufficient to illustrate the difference between financial market structures. Table 6 compares results for the two-bonds-two-equites case with autarky and a single noncontingent bond. The numbers shown in this table are the ratio of the standard deviation of the real exchange rate yielded by optimal policy relative to the standard deviation yielded by inflation targeting. The lower the reported number the more stabilising optimal policy is relative to inflation targeting, while a reported number close to unity implies almost no stabilising effect of optimal policy relative to inflation targeting.

\footnotetext{
${ }^{21} \mathrm{LCP}$ plays a significant role in Corsetti et al $(2010,2018)$ because their welfare results are most significant when the trade balance is insensitive to changes in the terms of trade or when the terms of trade are insensitive to change in the nominal exchange rate (i.e. the LCP case). Our results are driven by the link between portfolio allocation and monetary policy. This link is relatively independent of whether firms are following PCP or LCP strategies, hence there are no significant differences between the results in Tables 4 and 5 .
} 
Table 6: Alternative financial market structures (PCP)

\begin{tabular}{llllll}
\hline \hline Trade elasticity, $\theta$ & 0.25 & 0.5 & 0.75 & 1.5 & 3 \\
\hline & & & & & \\
Bonds and equities & 0.70 & 0.64 & 0.59 & 0.48 & 0.36 \\
Single bond & 0.98 & 0.87 & 1.00 & 1.00 & 1.00 \\
Autarky & 0.99 & 0.93 & 0.99 & 1.00 & 1.00 \\
& & & & & \\
\hline \hline
\end{tabular}

Note: The numbers shown in this table are the ratio of the standard deviation of the real exchange rate

yielded by optimal policy relative to the standard deviation yielded by inflation targeting.

It is apparent that, for values of $\theta$ not close to $1 / 2$, the stabilising effect of optimal policy is very small in the autarky and single-bond cases. It is only when $\theta$ is close to $1 / 2$ that the stabilising effect of optimal policy is non-trivial. By contrast, in the two-bondstwo-equites case the stabilising effect of optimal policy is significant at all values of $\theta$. These results match the results derived in the simple model and they confirm that the basic mechanism illustrated in Figure 1 continues to operate in the more general model. ${ }^{22}$

\subsection{Different Combinations of shocks}

The results reported in Tables 4 and 5 confirm that the results illustrated in the simple model carry over to a more general structure. Note however, in the context of the simple model, the mechanism that generated large differences between optimal policy and inflation targeting depended on the trade-off between choosing a portfolio that could hedge two different sources of shocks. In the case of the simple model this was the tradeoff between hedging TFP shocks and taste shocks. The generalised model contains 6 types of shock. It is useful to consider the role of each shock in generating a hedging trade-off. To do this we consider the implications of removing each source of shock in

\footnotetext{
${ }^{22}$ Notice in Tables 4 and 5 that, unlike in the two-bond case in Table 2, the divergence between optimal policy and inflation targeting does not appear to decline in the vicinity of $\theta \rho=1$. The special role of $\theta \rho=1$ arises in the simple model in Table 2 because there are only two sources of shocks. As explained above, in the vicinity of $\theta \rho=1$, the terms of trade provide hedging against TFP shocks and, in the simple model, allows bond allocation to focus on taste shocks. The general model illustrated in Tables 4 and 5 contains multiple sources of risk so the hedging properties of the terms of trade in the vicinity of $\theta \rho=1$ are much less significant.
} 
turn (while retaining the other five). Table 8 shows the stabilising effect of optimal policy (i.e. the ratio of the standard deviation of the real exchange rate gap yield by optimal policy relative to inflation targeting). Here we focus on the PCP case with $\theta=1.5$. In each column we remove one shock and retain the other five.

Table 7 shows clearly that it is taste shocks that are particularly important in generating a hedging conflict. It is only when taste shocks are present (in combination with the other shocks) that optimal policy generates a significant degree of stabilisation relative to inflation targeting. When taste shocks are excluded there is virtually no stabilising effect of optimal policy relative to inflation targeting. This indicates that the other five shocks, even though they are uncorrelated with each other, produce effects on asset returns and the marginal utility of consumption that are so similar that the equilibrium portfolio of bonds and equities provides a good hedge for all shocks regardless of the choice of policy rule coefficients. Taste shocks, on the other hand, appear to generate effects on asset returns and marginal utility which are very different from the effects of the other shocks, so taste shocks create a hedging conflict with the other shocks which does not otherwise arise.

The results illustrated in Table 7 obviously raises the question: why do taste shocks play such a significant role? That answer to this is that taste shocks, by their very nature, directly impinge on the marginal utility of consumption. All of the other five shocks only indirectly affect the marginal utility of consumption via their effects on household disposable income. Any portfolio which hedges disposable income fluctuations will therefore be a reasonably good hedge against all the other five shocks simultaneously, while it may or may not be a good hedge against taste shocks. ${ }^{23}$ A further intriguing question therefore arises: are there other forms of shock which give rise to a hedging conflict of the form generated by taste shocks? We leave this question to further research.

\subsection{Parameter variations}

We now briefly consider the effects of varying a number of key parameters away from their benchmark values. Table 8 summarises the effects of varying the share of home and foreign goods in the consumption basket, $\gamma$, the degree of risk aversion, $\rho$, and the elasticity of labour supply, $1 / \phi$. For each parameter variation we show a range of values for $\theta$ and for

\footnotetext{
${ }^{23}$ Indeed, once taste shocks are excluded, not only is there is no significant hedging conflict between the other five shocks, it also appears that the available assets are such a good hedge against those five shocks that there is in any case no significant trade-off between inflation targeting and risk sharing.
} 
Table 7: Omitting shocks

\begin{tabular}{|c|c|c|c|c|c|c|}
\hline Omitted shock(s) & & $\begin{array}{l}\text { TFP+ } \\
\text { News }\end{array}$ & $\begin{array}{c}\text { Gov } \\
\text { spending }\end{array}$ & $\begin{array}{l}\text { Labour } \\
\text { supply }\end{array}$ & Taste & Mark-up \\
\hline \multirow[t]{5}{*}{ Policy rule } & $\delta_{Y}$ & 0.129 & 0.129 & 0.129 & 0.129 & 0.000 \\
\hline & $\delta_{\tau}$ & -0.013 & -0.026 & -0.049 & 0.001 & 0.000 \\
\hline & $\delta_{\mathcal{D}}$ & -1.349 & -0.565 & 0.977 & -0.016 & -0.986 \\
\hline & $\delta_{\mathcal{L}}$ & 0 & 0 & 0 & 0 & 0 \\
\hline & $\delta_{\pi}$ & 0.998 & 1.000 & 0.996 & 0.999 & 0.997 \\
\hline Welfare difference & & 0.0034 & 0.0039 & 0.0038 & 0.0000 & 0.0038 \\
\hline \multirow{4}{*}{ Portfolio (optimal) } & (bonds) & 28.4 & 19.3 & 11.8 & 21.6 & 23.1 \\
\hline & (equities) & -4.7 & 16.0 & 33.1 & 0.1 & 7.4 \\
\hline & (bonds) & 17.3 & 21.2 & 21.1 & 21.5 & 21.1 \\
\hline & (equities) & 3.9 & 0.1 & 0.3 & 0.0 & 0.4 \\
\hline St Dev PPI Inflation & (optimal) & 0.0060 & 0.0055 & 0.0084 & 0.0031 & 0.0063 \\
\hline \multirow[t]{2}{*}{ St Dev Output gap } & (optimal) & 0.042 & 0.095 & 0.093 & 0.089 & 0.093 \\
\hline & (inf tar) & 0.167 & 0.196 & 0.195 & 0.092 & 0.194 \\
\hline \multirow[t]{2}{*}{ St Dev RER gap } & (optimal) & 0.26 & 0.63 & 0.62 & 0.60 & 0.63 \\
\hline & (inf tar) & 1.12 & 1.32 & 1.32 & 0.60 & 1.32 \\
\hline
\end{tabular}

Note: Each column in this table shows the outcome when one type of shock is omitted. Each column shows the optimal policy rule coefficients, the welfare difference between optimal policy and inflation targeting, standard deviations and equilibrium portfolios for optimal policy and inflation targeting. Welfare is measured in terms of the equivalent percentage of steady-state consumption. Standard deviations are measured in percentages. Portfolio holdings are measured relative to steady state GDP. 
Table 8: Parameter variations

\begin{tabular}{cccccc}
\hline \hline & \multicolumn{3}{c}{ Welfare difference $^{1}$} & \multicolumn{2}{c}{ St Dev RER gap $^{2}$} \\
$\theta$ & 0.5 & 1.5 & 0.5 & 1.5 \\
\hline & & & & & \\
& 0.6 & 0.0040 & 0.0045 & 0.28 & 0.24 \\
& 0.7 & 0.0037 & 0.0044 & 0.41 & 0.28 \\
& 0.8 & 0.0033 & 0.0041 & 0.55 & 0.37 \\
& 0.9 & 0.0029 & 0.0037 & 0.67 & 0.53 \\
& & & & & \\
$\rho$ & 0.5 & 0.0025 & 0.0037 & 0.84 & 0.75 \\
& 1 & 0.0026 & 0.0036 & 0.77 & 0.64 \\
& 2 & 0.0030 & 0.0038 & 0.64 & 0.48 \\
& 5 & 0.0042 & 0.0052 & 0.40 & 0.26 \\
& & & & & \\
& 0.5 & 0.0033 & 0.0050 & 0.61 & 0.50 \\
2 & 0.0030 & 0.0038 & 0.64 & 0.48 \\
5 & 0.0028 & 0.0033 & 0.68 & 0.47 \\
& 9 & 0.0027 & 0.0032 & 0.69 & 0.47 \\
\hline \hline
\end{tabular}

1. Welfare difference between optimal and inflation targeting

2. StDev(optimal policy)/StDev(inflation targeting)

each parameter combination we show the welfare difference between optimal policy and inflation targeting and also the ratio of the standard deviation of the real exchange rate gap for optimal policy relative to the standard deviation for inflation targeting.

The first set of results in Table 8 shows the effects of varying the share of home and foreign goods in the consumption basket, $\gamma$. This can be thought of as a measure of openness, where a value of $\gamma$ close to 0.5 implies a more open economy and a value of $\gamma$ close to unity implies a less open economy. The results in Table 8 show that the welfare gains from optimal policy are marginally larger for more open economies. It also appears that the stabilising effect of optimal policy on the real exchange rate gap is also more significant for more open economies.

The second set of results in Table 8 show the effects of varying the degree of risk 
aversion, $\rho$. The results show that the welfare gains for optimal policy appear to increase as risk aversion increases. The stabilising effect on the real exchange rate gap also increases as risk aversion increases.

The third set of results in Table 8 show the effects of varying the elasticity of labour supply, $1 / \phi$. The results show that the welfare gains from optimal policy are higher when labour supply is more elastic. The labour supply elasticity has only a minor effect on the stabilising effect of optimal policy on the real exchange rate gap.

Table 9 shows the effect of varying the parameter $\eta$ in the endogenous discount factor (for the case where $\theta=1.5$ ). This table shows that, in contrast to the effects of the parameters shown in Table 8 , varying $\eta$ has a potentially very significant effect on the size of welfare gains. A very small value of $\eta$ implies that the discount factor adjusts very gradually to changes in aggregate consumption. This in turn implies that transitory shocks can have very long lasting effects on net foreign assets. In the absence of any deliberate policy response, this tends to raise the variance of consumption and work effort and thus has potentially strong negative effects on welfare. Optimal policy tends to counter these effects by placing a stronger emphasis on the risk sharing gap in the policy rule (i.e. the parameter $\delta_{\mathcal{D}}$ ) for low values of $\eta$ (as can be seen in Table 9). A policy of inflation targeting on the other hand ignores the implications of volatile net foreign assets for welfare and thus the welfare performance of inflation targeting is significantly lower than optimal policy when $\eta$ is small. It therefore follows that, as shown in Table 9, the welfare gain from optimal policy is larger for small values of $\eta$. Note however that, for small values of $\eta$, the variances of consumption and work effort are unrealistically large, so the large welfare gains from optimisation are not empirically plausible.

\section{Conclusions}

Recent literature on monetary policy in open economies (Corsetti et al, 2010, 2018) shows that, when international financial trade is absent or restricted to a single noncontingent bond, there are significant internal and external trade-offs that prevent optimal policy from simultaneously closing all welfare gaps. In this case optimal monetary policy deviates from inflation targeting in order to offset real exchange rate misalignments. These simple models of financial market incompleteness provide important theoretical insights but they are obviously not good representations of modern financial markets. This paper therefore develops a more realistic model of incomplete markets, where there 
Table 9: Alternative values for $\eta$

\begin{tabular}{|c|c|c|c|c|c|c|}
\hline$\eta$ & & 0.0001 & 0.0005 & 0.001 & 0.005 & 0.01 \\
\hline \multirow{5}{*}{ Policy rule } & $\delta_{Y}$ & 0.129 & 0.129 & 0.129 & 0.129 & 0.129 \\
\hline & $\delta_{\tau}$ & 0.004 & 0.004 & 0.002 & -0.007 & -0.012 \\
\hline & $\delta_{\mathcal{D}}$ & -20.2 & -5.72 & -3.37 & -1.02 & -0.621 \\
\hline & $\delta_{\mathcal{L}}$ & 0 & 0 & 0 & 0 & 0 \\
\hline & $\delta_{\pi}$ & 0.999 & 0.999 & 0.999 & 0.998 & 0.996 \\
\hline Welfare difference & & 0.1481 & 0.0304 & 0.0156 & 0.0038 & 0.0024 \\
\hline \multirow{4}{*}{ Portfolio (optimal) } & (bonds) & 17.9 & 19.1 & 20.0 & 23.8 & 27.2 \\
\hline & (equities) & 19.1 & 16.3 & 14.3 & 5.8 & -2.0 \\
\hline & (bonds) & 19.9 & 20.0 & 20.1 & 21.1 & 22.0 \\
\hline & (equities) & 0.4 & 0.4 & 0.4 & 0.3 & 0.3 \\
\hline PPI Inflation & (optimal) & 0.0049 & 0.0053 & 0.0057 & 0.0074 & 0.0087 \\
\hline \multirow[t]{2}{*}{ Output gap } & (optimal) & 0.023 & 0.035 & 0.046 & 0.095 & 0.131 \\
\hline & (inf tar) & 1.064 & 0.483 & 0.349 & 0.196 & 0.188 \\
\hline \multirow[t]{2}{*}{ RER gap } & (optimal) & 0.10 & 0.21 & 0.29 & 0.64 & 0.88 \\
\hline & (inf tar) & 7.24 & 3.28 & 2.37 & 1.32 & 1.27 \\
\hline
\end{tabular}

Note: Each column shows the optimal policy rule coefficients, the welfare difference between optimal policy and inflation targeting, standard deviations and equilibrium portfolios for optimal policy and inflation targeting. Welfare is measured in terms of the equivalent percentage of steady-state consumption. Standard deviations are measured in percentages. Portfolio holdings are measured relative to steady state GDP. 
is international trade in multiple assets. The analysis shows that the presence of multiple assets creates a potentially powerful interaction between monetary policy and household portfolio allocation. This interaction is, by definition, not present when there is financial autarky or a single tradeable bond and this paper shows that the interaction with portfolio allocation can imply that optimal monetary policy generates a quantitatively much more significant stabilisation of the real exchange rate gap than implied by simpler models of financial market incompleteness.

This paper focuses on a model of imperfect financial markets where the imperfection simply takes the form of a restricted set of financial instruments (i.e. bonds and equities) which is insufficient to provide full international risk sharing. Devereux and Sutherland (2011b) show that the presence of collateral constraints can significantly alter the international transmission of shocks, especially in the case when there is trade in bonds and equity. In a companion paper (Senay and Sutherland, 2016) we analyse optimal monetary policy in a version of the above model which has been extended to incorporate collateral constraints. 


\section{References}

Beaudry, P. and F. Portier (2006) "Stock Prices, News, and Economic Fluctuations" American Economic Review, 96, 1293-1307.

Benigno, P. (2009) "Price Stability with Imperfect Financial Integration" Journal of Money, Credit and Banking, 41, 121-149.

Benigno, P. and M. Woodford (2005) "Inflation Stabilization and Welfare: The Case of a Distorted Steady State" Journal of the European Economic Association, 3, 1185-1236.

Benigno, G. and Benigno, P. (2003) "Price Stability in Open Economies" Review of Economics Studies 70, 743-764.

Bodenstein, M. (2010) "Trade Elasticities of Substitution and Equilibrium Dynamics" Journal of Economic Theory, 145, 1033-1059.

Calvo, G. A. (1983) "Staggered Prices in a Utility-Maximizing Framework" Journal of Monetary Economics, 12, 383-398.

Christiano, L., M. Eichenbaum and C Evans (2005) "Nominal rigidities and the dynamic effects of a shock to monetary policy" Journal of Political Economy, 113, 1-45.

Clarida, R., Gali J. and Gertler, M. (2002) "A Simple Framework for International Monetary Policy Analysis" Journal of Monetary Economics, 49, 879-904.

Cole, H. L. and M Obstfeld (1991) "Commodity trade and international risk sharing: How much do financial markets matter?" Journal of Monetary Economics, 28, 3-24.

Corsetti, G., L. Dedola and S Leduc (2010) "Optimal Monetary Policy in Open Economies" in Handbook of Monetary Economics Vol.3B Ben Friedman and Michael Woodford (eds)., Elsevier, 862-933.

Corsetti, G., L. Dedola and S Leduc (2018) "Demand Imbalances, Exchange Rate Misalignment and Optimal Monetary Policy Trade-offs" Centre for Economic Policy Research Discussion Paper no 18850.

Damjanovic, T., Damjanovic, V., and Nolan, C. (2008) "Unconditionally optimal monetary policy" Journal of Monetary Economics, 55, 491-500. 
Devereux, M. and A. Sutherland (2008) "Financial globalization and monetary policy" Journal of Monetary Economics, 55, 1363-1375.

Devereux, M. and A. Sutherland (2010a) "Country portfolio dynamics" Journal of Economic Dynamics and Control, 34, 1325-1342.

Devereux, M. and A. Sutherland (2010b) "Valuation effects and the dynamics of net external assets" Journal of International Economics, 80, 129-143.

Devereux, M. and A. Sutherland (2011a) "Solving for country portfolios in open economy macro models" Journal of the European Economic Association, 9, 337-369.

Devereux, M. and A. Sutherland (2011b) "Evaluating International Financial Integration Under Leverage Constraints" European Economic Review, 55, 427-442.

Devereux, M., O. Senay, and A. Sutherland (2014) "Nominal Stability and Financial Globalization" Journal of Money, Credit and Banking 46, 5, 921-939.

De Paoli, B. (2010) "Monetary Policy under Alternative Asset Market Structures: The Case of a Small Open Economy" Journal of Money, Credit, and Banking, 41, 1301-1330.

Engel, C. (2011) "Currency misalignments and optimal monetary policy: a reexamination" American Economic Review, 101, 2796-2822.

Fanelli, S. (2017) "Monetary Policy, Capital Controls and International Portfolios" unpublished manuscript, MIT

Gali, J. and Monacelli, T. (2005) "Monetary Policy and Exchange Rate Volatility in a Small Open Economy" Review of Economics Studies, 72, 707-734.

Rabitsch, K. (2012) "The Role of Financial Market Structure and the Trade Elasticity for Monetary Policy in Open Economies" Journal of Money Credit and Banking, 44, 603-629.

Samuelson, P. (1970) "The Fundamental Approximation Theorem of Portfolio Analysis in terms of Means, Variances and Higher Moments" Review of Economic Studies, 37, $537-542$.

Schmitt-Grohe, S. and M. Uribe (2003) "Closing Small Open Economy Models" Journal of International Economics, 59, 137-59. 
Senay, O. and A. Sutherland (2013) "The Timing of Asset Trade and Optimal Policy in Dynamic Open Economies" Macroeconomic Dynamics, 17, 1543-1573.

Senay, O. and A. Sutherland (2016) "Country Portfolios, Collateral Constraints and Optimal Monetary Policy" unpublished manuscript, University of St Andrews.

Smets F. and R. Wouters (2003) "An estimated dynamic stochastic general equilibrium model of the euro area" Journal of the European Economic Association, 5, 1123-1175.

Smets F. and R. Wouters (2005) "Comparing shocks and frictions in US and euro area business cycles: a Bayesian DSGE approach" Journal of Applied Econometrics, 20, 161-183.

Smets F. and R. Wouters (2007) "Shocks and frictions in US business cycles: a Bayesian DSGE approach" American Economic Review, 97.

Tille, C. and E. van Wincoop (2010) "International capital flows" Journal of International Economics, 80, 157-175.

Woodford, M. (2003) Interest and Prices: Foundations of a Theory of Monetary Policy Princeton University Press, Princeton, NJ. 